\title{
Developing a national programme of flood risk management measures: Moldova
}

\author{
David Ramsbottom ${ }^{1, a}$, Enrico Frank ${ }^{2}$, Alain Weisgerber ${ }^{1}$ and Marco Beros ${ }^{3}$ \\ ${ }^{1} \mathrm{HR}$ Wallingford, Wallingford, Oxfordshire, OX10 8BA, UK \\ ${ }^{2}$ Beta Studio, Via Guido Rossa 29/A - 35020 Ponte S. Nicolo, Padua, Italy \\ ${ }^{3}$ European Investment Bank, 100 boulevard Konrad Adenauer, L-2950, Luxembourg
}

\begin{abstract}
A Technical Assistance project funded by the European Investment Bank has been undertaken to develop a programme of flood risk management measures for Moldova that will address the main shortcomings in the present flood management system, and provide the basis for long-term improvement. Areas of significant flood risk were identified using national hydraulic and flood risk modelling, and flood hazard and flood risk maps were then prepared for these high risk areas. The flood risk was calculated using 12 indicators representing social, economic and environmental impacts of flooding. Indicator values were combined to provide overall estimates of flood risk. Strategic approaches to flood risk management were identified for each river basin using a multi-criteria analysis. Measures were then identified to achieve the strategic approaches. A programme of measures covering a 20-year period was developed together with a more detailed Short-Term Investment Plan covering the first seven years of the programme. Arrangements are now being made to implement the programme. The technical achievements of the project included national hydrological and hydraulic modelling covering 12,000 km of river, the development of 2dimensional channel and floodplain hydraulic models from a range of topographic and bathymetric data, and an integrated flood risk assessment that takes account of both economic and non-monetary impacts.
\end{abstract}

\section{Introduction}

\subsection{Background}

Following severe floods in 2008 and 2010, the Government of Moldova requested assistance to improve flood protection throughout the country.

A technical assistance project to develop a programme of flood risk management measures was financed by the European Investment Bank (EIB) under the Eastern Partnership Technical Assistance Trust Fund (EPTATF).

The Fund was established in 2010 with a view to enhancing the quality and development impact of the European Investment Bank's Eastern Partnership operations through the financing of pre-feasibility and feasibility studies, institutional and legal appraisals, environmental and social impact assessments for potential investments, project management support and capacity building for the promoters during the implementation of investment projects, as well as other upstream studies.

The approach set out in the EU Floods Directive has been adopted and extended in order to provide a programme for immediate implementation that would address the main shortcomings in the present flood management system, and provide the basis for the long-term improvement of flood management in Moldova.

A Master Plan for flood risk management planning has been developed that provides a phased investment programme of flood management measures for rivers in Moldova covering a 20-year period and a Short Term Investment Plan covering the next seven years.

\subsection{The river system in Moldova}

The river system in Moldova consists of two large international rivers, the Dniester and the Prut, and a large number of smaller rivers. The Prut forms the western border of Moldova with Romania. The Dniester forms the border between Moldova and Ukraine in the north of the country and then passes through Moldova for a distance of $475 \mathrm{~km}$ before reentering Ukraine.

$67 \%$ of Moldova drains into the Dniester, 24\% into the Prut and 9\% into the Black Sea or the Danube via tributaries that cross the southern border of the country into Ukraine. The largest river in Moldova is the River Răut, which drains about $23 \%$ of the country. There are a large number of smaller rivers in

\footnotetext{
${ }^{a}$ Corresponding author: $\underline{\text { d.ramsbottom } @ \text { hrwallingford.com }}$
} 
generally narrow valleys. The rivers in Moldova have about $3,000 \mathrm{~km}$ of flood defences which consist of earth banks (dykes). Very little maintenance has been carried out in the last 25 years and some of the dykes are in poor condition. There were some serious bank failures on the two large international rivers during the most recent major flood in 2010 and some of the dykes on the smaller rivers are no longer effective.

There are nearly 5,000 dams and reservoirs in Moldova ranging from two large hydroelectric dams, the Dubasari dam on the Dniester and the Costești Stânca dam on the Prut, to many small reservoirs near villages that were built for water supply and other purposes. Whilst these reservoirs can have beneficial impacts on flooding by attenuating flood flows in the rivers, there is a risk of dam failure with potentially catastrophic consequences. The management of this risk is included in the Master Plan.

\subsection{Flood management legislation in Moldova}

Moldova, as it is not a Member of the EU, had neither implemented the EU Water Framework Directive (2000/60/EC) nor the EU Floods Directive (2007/60/EC). However on 27 June 2014 the Republic of Moldova signed an Association Agreement and Free Trade Agreement with the EU.

Under the Association Agreement the Republic of Moldova undertakes to gradually approximate its legislation to the EU legislation listed in the Annex XI to the agreement, including the EU Floods Directive and the EU Water Framework Directive.

The EU Floods Directive is partially transposed into the Government Decision GD n. 887 of $11 / 11 / 2013$. This law integrates floods risk management planning of river basins and establishes the procedures and mechanisms for assistance to the population affected by floods.

The EU Water Framework Directive is partially transposed into the Government Decision GD n. 866 of $01 / 11 / 2013$. This law regulates the preparation and review of river basin management plans.

Thus the approach adopted in this project of implementing the steps set out in the EU Floods Directive is consistent with current legislation in Moldova.

\subsection{Stages in the development of the Master Plan}

The Master Plan was developed in the following main stages:

- Preliminary Flood Risk Assessment (Task 1);

- Hydraulic modelling and preparation of flood hazard maps (Task 2);

- Assessment of flood risk (Task 3);

- Identification of objectives and strategies for flood risk management (Task 4);

- Identification of measures for flood risk management (Task 5);

- Development of the phased investment programme (Task 6) and the Short Term
Investment Plan (Task 7).

The general approach to developing the Master Plan including the development of objectives and strategies for flood risk management generally follows EIB guidance [1].

\section{Preliminary Flood Risk Assessment}

\subsection{Summary}

The Preliminary Flood Risk Assessment (PFRA) included reviews of the existing flood protection infrastructure in Moldova and the institutional arrangements for managing flood risk. Historic flooding was also reviewed including the major floods on the Dniester and the Prut in 2008 and 2010.

High level hydrological and hydraulic modelling was carried out for all 12,000 km of rivers in Moldova in order to identify the areas with greatest flood risk, for detailed analysis in subsequent stages of the project.

The flood risk was calculated by overlaying the flood hazard map with a land use map, and weighting each land use type according to the flood impact. The risk was presented on a flood risk maps as high, moderate or low.

The high risk areas were selected for detailed assessment and covered a total river length of 3,400 $\mathrm{km}$. This includes the full length of the Dniester and the Prut rivers that border or pass through Moldova.

This national modelling formed a vital component of the development of the Master Plan, and is described in further detail in Section 2.2.

\subsection{National flood modelling}

\subsubsection{Rationale}

The standard method for carrying out a flood hazard assessment involves an initial hydrological analysis in order to calculate flood flows at the upstream end and lateral inflows into the river reaches of interest.

The methodology for carrying out the hydrological analysis will depend on the type, quantity and quality of data available. The preferred choice is to rely on directly measured flow at river gauging stations. However this is rarely available with sufficient density.

Rainfall data tends to be recorded at a larger number of locations, as is the case in Moldova. In this situation, the hydrological analysis typically consists in processing the topography data (e.g. Digital Elevation Model, DEM) in order to derive hydrological catchment boundaries at an appropriate level of detail. A rainfall-runoff model is then created for each of the catchments to assess flow based on rain-gauge records, soil and land cover type, area and slope. 
In order to undertake a national hydrological analysis, a direct 2D rainfall-runoff method was developed and applied, as described below.

\subsubsection{Direct 2D rainfall-runoff}

A DEM for the whole of Moldova was constructed using a national DEM provided by the Moldova government, which has a horizontal resolution of 35 $\mathrm{m}$. It was also necessary to include river catchments that drain into Moldova from other countries, and the DEM for these catchments was obtained from a coarse resolution satellite DEM (SRTM).

Rainfall profiles corresponding to rain gauges distributed within the country were directly applied to the elements in the DEM. The country was divided using Thiessens polygons in order to identify the area assigned to each rainfall profile.

Infiltration losses can be applied using a variety of models: using a constant infiltration rate, using a fixed percentage of the net rainfall which becomes runoff, or using the Horton infiltration model where the infiltration rate varies according to the soil saturation. Given the high-level nature of the study, a simple fixed runoff percentage rate was selected.

Although it would be possible to implement evaporation in the modelling, the effect of evaporation was neglected because its impact on flood events where the volume of water is large and the duration is relatively short is small.

This method has the great advantage of not requiring any preliminary topography analysis to derive sub-catchments: the runoff follows the steeper slopes and naturally concentrates in drainage paths. It then flows into streams and rivers.

This method also removes the need to estimate a priori the catchments' times of concentration (which is a critical factor in the peakiness of the runoff and therefore maximum flow) as the flow transport is in theory directly calculated by the $2 \mathrm{D}$ engine.

A limitation to applying this method on such a scale has in the past been the processing power. The model covered the country with approximately 3 million mesh elements, which are all wet and therefore computationally active.

This puts a lot of strain on the computers carrying out the simulations. However the use of modern Graphics Processing Units (GPU) allows carrying out these simulations roughly an order of magnitude faster than with a multi-core Central Processing Unit (CPU), making this approach a practical possibility.

Flows for the Dniester and Prut rivers were based on gauged flow records. Most of the flood volumes come from outside Moldova and there are good gauge records for both rivers.

\subsubsection{Results}

Comparing the results with calibration data, the modelled flows tended to be peakier than the recorded flows, with the peak arriving earlier than predicted and with greater intensity. In order to reduce this discrepancy, a much greater roughness than anticipated was necessary. Further testing has also shown that the size of elements in the model mesh affects the results, which therefore adds uncertainty to the flow predictions. These areas are currently under active research.

Despite these limitations, the direct 2D rainfall method has enabled the production of a national flood hazard map which shows the locations of areas with the greatest flood hazard.

Combining this information with land use (and therefore vulnerability), it has been possible to produce a preliminary map of relative flood risk, which has enabled identification of the areas with the greatest flood risk.

A Geographical Information System (GIS) procedure was used to calculate relative values of risk per kilometre for all of the rivers, thus providing an auditable method of selecting the areas of greatest flood risk. Different land uses were assigned different values of impact, with the greatest impact applying to residential areas in cities, towns and villages.

The flood hazard map for Moldova is shown on Figure 1. The dendritic nature of the river system is apparent. The largest floodplains are on the Dniester and the Prut, particularly in the lower reaches.

A 3D view of flood hazard for part of Moldova is shown on Figure 2. The large flooded area is a natural floodplain upstream of a gorge on the River Răut.

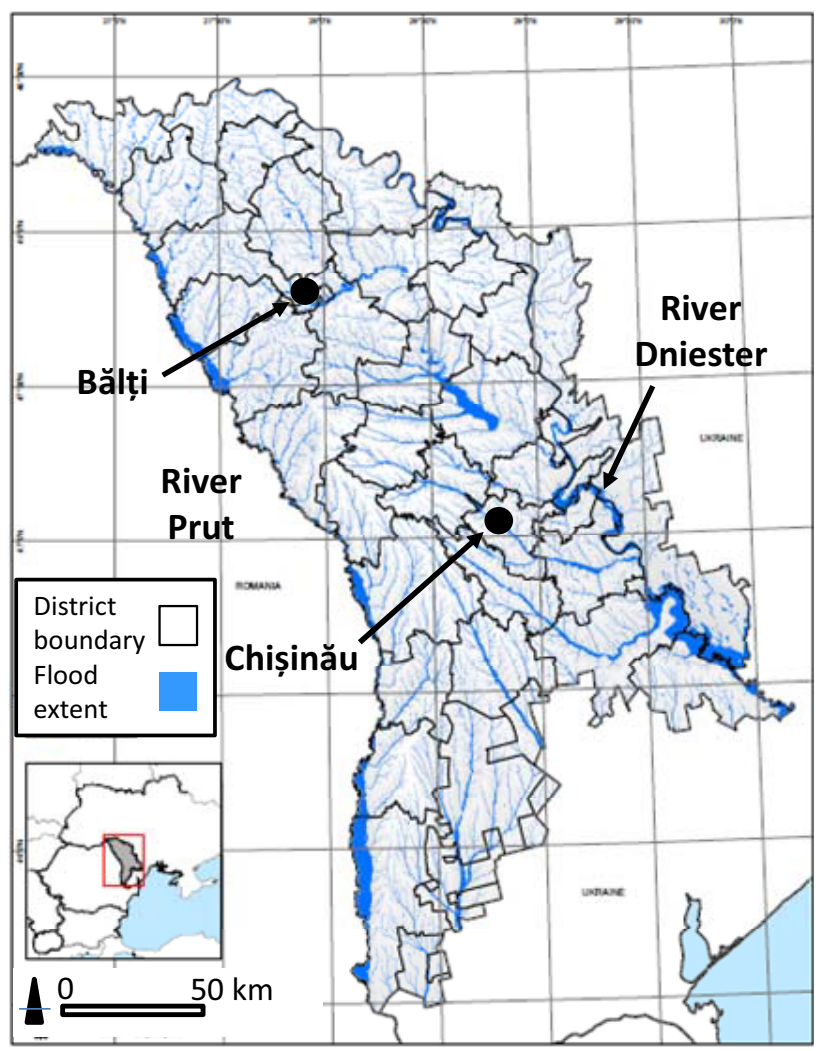

Figure 1. National flood hazard map 


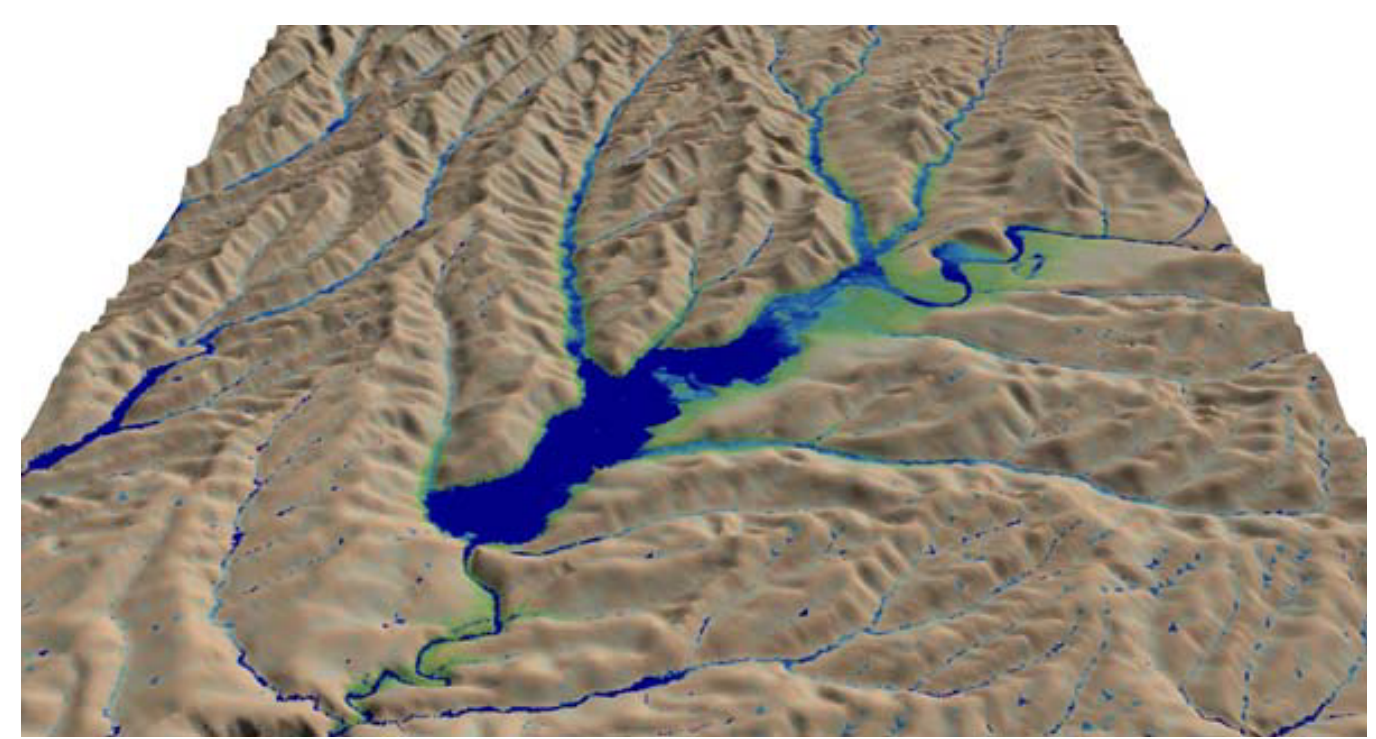

Figure 2. 3D view of a section of the national flood hazard map

\section{Flood hazard modelling}

Detailed hydraulic models were constructed for the $3,400 \mathrm{~km}$ of rivers that were identified for detailed assessment including the full length of the Dniester and the Prut rivers that border or pass through Moldova.

\subsection{Data}

Data collected for the hydraulic modelling and flood hazard mapping included detailed topographical data from a number of different surveys. A Light Detection And Ranging (LiDAR) survey for many of the rivers together with river channel and dyke surveys were carried out as part of the project. In addition, existing topographical data was collected from other projects in Moldova.

The Agency of Land Relations and Cadastre provided LiDAR data for the central part of the country, funded by the Austrian Development Cooperation. River channel bathymetry and floodplain topography data for the lower part of the Dniester was provided by the Dniester III project [2]. This project also provided information on climate change [3].

DEMs for each river basin were created by combining the various sets of topographical data. Complete 2D ground models that included the river channels and floodplains were created by combining the river cross-section surveys with floodplain data. This important step in model development is described in Section 3.2.

A wide range of other data was collected for the detailed modelling including information on the dam structures and operational procedures. This included collaboration with other projects including a project to improve the operation of the Costeşti Stânca dam on the River Prut [4].

\subsection{Creation of 2D models from 1D channels and 2D floodplains}

\subsubsection{Background}

The classic and widely-used method for river flood modelling is to use a one-dimensional (1D) representation for the river channels and a twodimensional (2D) representation for the floodplain [57]. This stems from two reasons:

- Limited channel bathymetry data, which in the vast majority of cases is available in the form of $1 \mathrm{D}$ cross-sections.

- Limited possibilities to represent structures such as bridges and gates directly in 2D.

- Limited computer resources, which constrain the extent and resolution of $2 \mathrm{D}$ domains.

This 1D-2D modelling approach is usually reasonable for flood modelling. However this approach is prone to some limitations:

- Time needs to be spent to determine the best location for the 1D-2D boundaries. This is straightforward in defended rivers (the boundary should follow the embankment crests where possible), but becomes more complex in the case of undefended rivers, or in highly meandering rivers.

- The linking of $1 \mathrm{D}-2 \mathrm{D}$ domains in existing modelling software does not conserve momentum. This means that the flow direction at the boundary of the $2 \mathrm{D}$ domain will always be normal to the boundary, misrepresenting the skewed flow that can occur when rivers spill into the floodplain.

- The linking between the 1D and 2D domains requires additional calculation, and can lead to instabilities due to flow recirculation which partially cancels the gain from using 
the less resource intensive 1D model for the channel.

As shown earlier, the use of GPUs can significantly decrease $2 \mathrm{D}$ simulations run time, and allows the use of either larger or more detailed meshes. This has been used here in order to represent river channels directly within the $2 \mathrm{D}$ mesh, via elements small enough to capture the bathymetry of rivers.

An advanced meshing method has been used in order to optimise the mesh, so as to refine the mesh where fine details are most needed (i.e. river channels, flood defences and other floodplain features controlling the flow) and coarsen it in less critical places (e.g. flat areas and higher ground that is less likely to flood).

It is now also possible to directly represent structures such as bridges or the gates of dams within the $2 \mathrm{D}$ domain in the modelling software used in the study (InfoWorks ICM).

The method requires careful preparation of a DEM where all the necessary topography and bathymetry from different sources are combined into a single 2D surface.

\subsubsection{Creating the DEM}

In order to create a consistent topography and bathymetry DEM, the first step was to prepare the topography for the whole country using the best available data at any single location. This consisted of:

- High resolution LiDAR data either already available from other projects or specifically produced for the study.

- Medium resolution DEM with a $35 \mathrm{~m}$ horizontal grid derived from satellite stereo images for most of the remaining part of the country.

- Coarse resolution satellite DEM (e.g. SRTM) for areas not covered by the more detailed DEMs and areas outside the country which are hydrologically linked to the study area.

- These datasets were combined giving priority to the best quality data, and minimising the discrepancy at the boundaries between layers.

The second step consisted of creating a DEM of the river bathymetry. Bathymetry obtained from a boat mounted sonar survey was available in the lower part of the River Dniester from the Dniester III project [2]. However for most of the River Dniester, the River Prut and for some smaller rivers only 1D cross sections were surveyed.

Software has been developed as part of the inhouse HR Wallingford research programme that interpolates a 2D surface along the river channels based on the river $1 \mathrm{D}$ cross sections. A straight interpolation would not lead to realistic results. Skew in the source cross sections was corrected, and the impact of contraction/expansion in-between cross sections was also taken into account, so that the interpolated channel width matches the actual river channel width at all locations.

Finally the topography and bathymetry have been merged in a single 2D surface which was used for the 2D model. Owing to the method used to derive the bathymetry surface, the discrepancies between the topography and bathymetry were generally small. In areas where the bathymetry levels were higher than the topography levels, the bathymetry levels were corrected using the adjacent topography levels.

Figure 4(a) shows an example of 1D river channel domain and a 2D floodplain domain, and Figure 4(b) shows the 2D channel and floodplain domain derived using this process. Figure 5 shows a $3 \mathrm{D}$ view of a section of the resulting $2 \mathrm{D}$ channel and floodplain.

\subsection{Model results}

Hydraulic modelling for the $3,400 \mathrm{~km}$ of river was undertaken for floods with annual exceedance probabilities of $1 \%, 0.5 \%$ and $0.1 \%$ (return periods of 100,200 and 1,000 years respectively). National flood hazard maps were prepared showing the flood extents for these events with and without the flood protection dykes. In addition, dam break modelling and mapping was carried out to identify the areas that would be affected by dam failures.

A small section of a flood hazard map is shown on Figure 3. Detailed maps showing flood depth and velocities were produced for each of the floods with different annual exceedance probabilities.

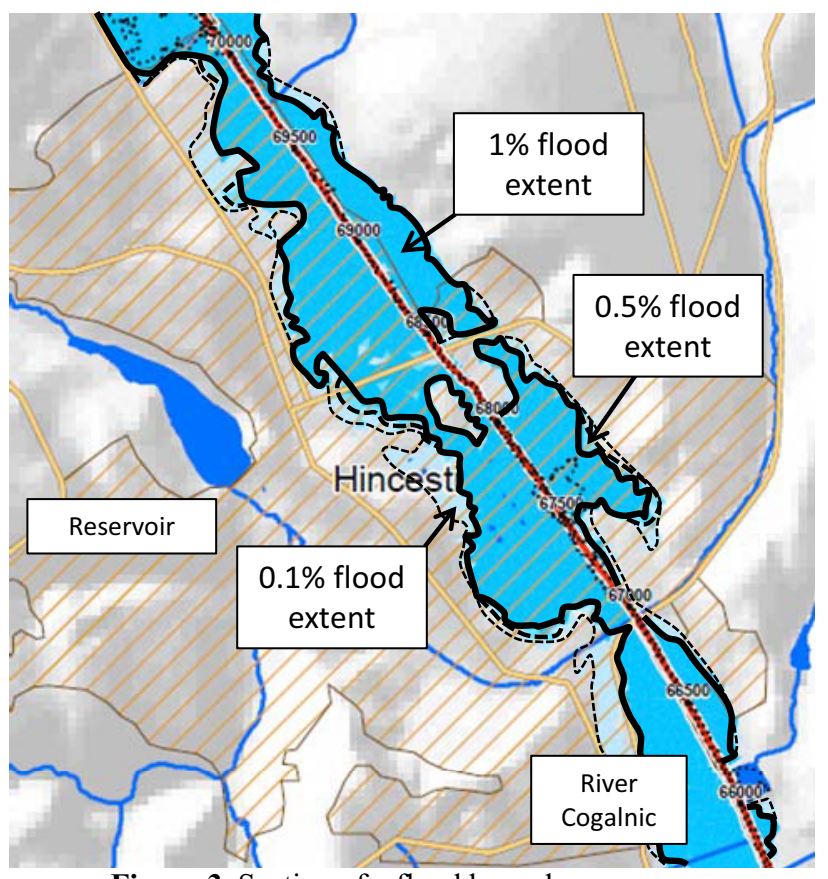

Figure 3. Section of a flood hazard map

It was found that for these large flood events, most of the existing flood defences were overtopped. In addition, the floods generally filled the river valleys and therefore the differences in flood extent between the $1 \%, 0.5 \%$ and $0.1 \%$ were small. However the 
differences in flood depths were large, typically in the range $0.3 \mathrm{~m}$ to $3 \mathrm{~m}$ depending on the size of river.

A climate change impact assessment was also carried out, in which the impacts of potential increases in future flood flows were investigated. The same pattern was observed: small changes in flood extent but large changes in flood depth.

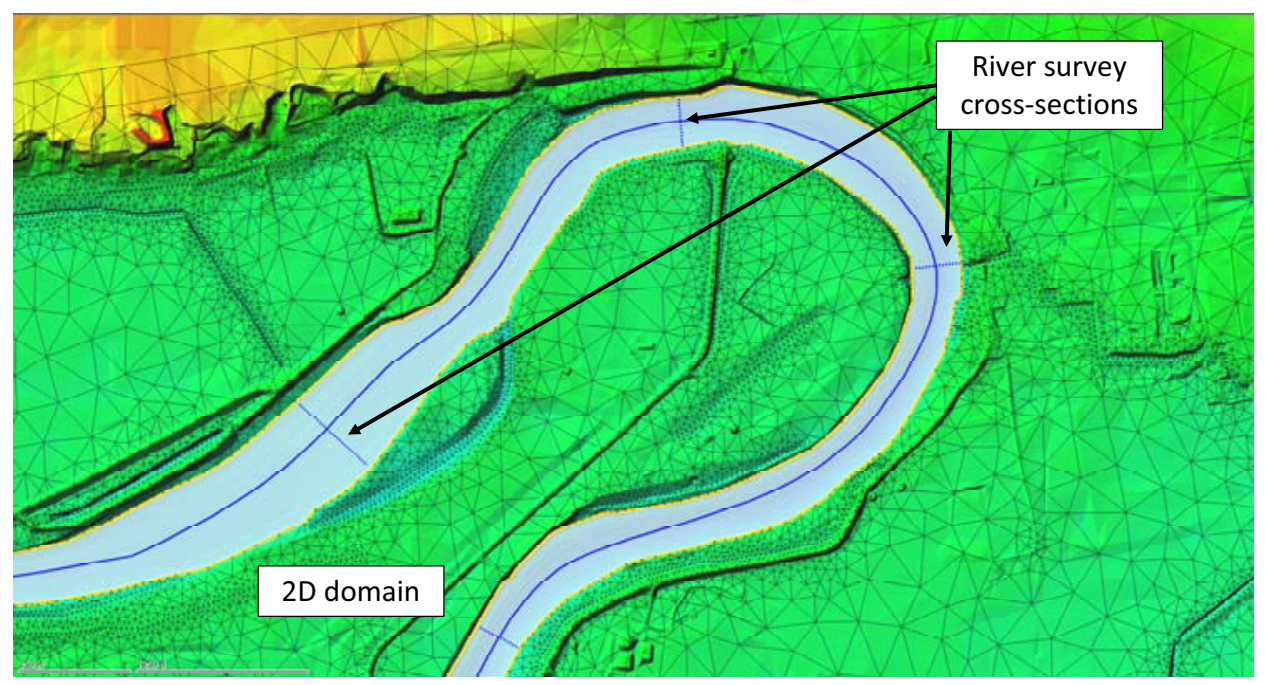

Figure 4 (a). 1D river channel domain and 2D floodplain domain

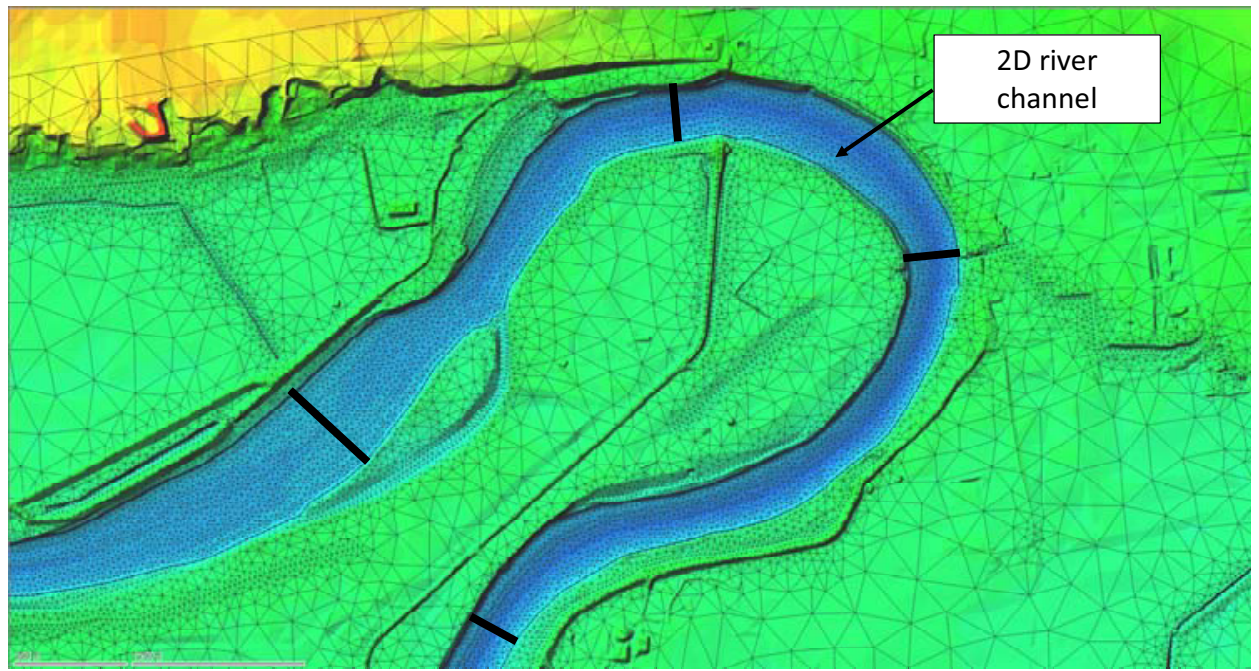

Figure 4 (b). 2D river channel and floodplain domain

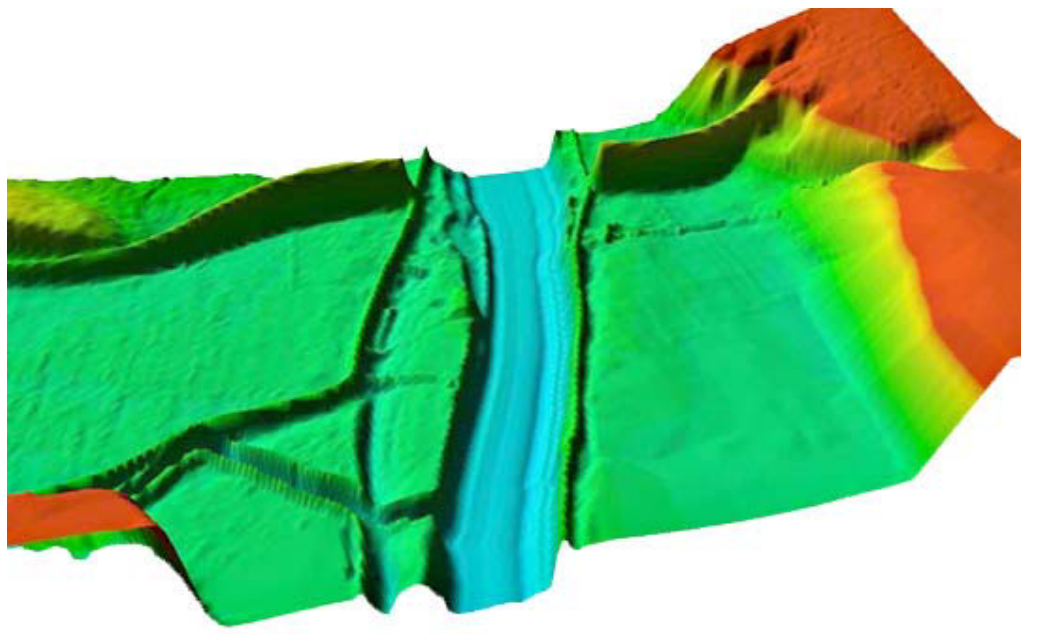

Figure 5. 3D view of a section of $2 \mathrm{D}$ river channel and floodplain 


\subsection{Hydropower potential}

An assessment of hydropower potential was also carried out, based on the amount of hydropower that could be generated from the existing dams (excluding the two major dams on the Dniester and the Prut, which already generate hydropower). The total hydropower potential was estimated to be about 1,400 $\mathrm{kW}$ and the annual energy production was estimated to be about 8,200 MWh.

\section{Flood risk assessment}

The flood risk was calculated using twelve indicators representing human, economic and environmental impacts. These included the effects of flooding on people, property damage, agricultural damage, effects of flooding on environmental and cultural sites, and pollution.

\subsection{The flood risk indicators}

The twelve flood risk indicators are shown in Table 1.

\begin{tabular}{|c|c|c|}
\hline $\begin{array}{l}\text { Categories } \\
\text { of impacts }\end{array}$ & & Flood risk indicators \\
\hline \multirow{5}{*}{$\begin{array}{l}\text { Human } \\
\text { impacts }\end{array}$} & HU1 & $\mathrm{N}^{\circ}$ of affected people \\
\hline & HU2 & Number of severely affected people \\
\hline & HU3 & $\begin{array}{l}\text { Number of very severely affected } \\
\text { people }\end{array}$ \\
\hline & $\mathrm{HU} 4$ & $\begin{array}{l}\text { Number of water supply points } \\
\text { flooded }\end{array}$ \\
\hline & HU5 & $\begin{array}{l}\text { Length of key infrastructure flooded } \\
\text { (main roads, railways) }\end{array}$ \\
\hline \multirow{3}{*}{$\begin{array}{l}\text { Economic } \\
\text { impacts }\end{array}$} & EC1 & $\begin{array}{l}\text { Damages for residential area (cities, } \\
\text { towns, villages) }\end{array}$ \\
\hline & EC2 & $\begin{array}{l}\text { Damages for non-residential area } \\
\text { (industrial and commercial) }\end{array}$ \\
\hline & EC3 & Agriculture damages \\
\hline \multirow{4}{*}{$\begin{array}{l}\text { Environmental } \\
\text { impacts }\end{array}$} & EN1 & Area of environmental sites flooded \\
\hline & EN2 & $\mathrm{N}^{\circ}$ of heritage sites flooded \\
\hline & EN3 & $\begin{array}{l}\mathrm{N}^{0} \text { of pollution sources (WWTP, oil } \\
\text { stations, waste disposal sites ...) } \\
\text { flooded }\end{array}$ \\
\hline & EN4 & Area of diffuse source of pollution \\
\hline
\end{tabular}

Table 1. Flood risk indicators

The distinction between indicators HU1, HU2 and HU3 was based on the flood depth $(d)$ and the flow velocity $(v)$ obtained from the hydraulic modelling results, as follows [8]:

For severely affected people: $(d .(v+0.5))>1.5)$

For very severely affected people: $(d .(v+0.5))>2.5)$

\subsection{Calculation of the flood risk}

The flood risk was evaluated by calculating annual average impacts for each indicator and then combining the impacts to obtain the total risk.

Damages for properties were calculated using depth-damage curves, as indicated on Figure 6.

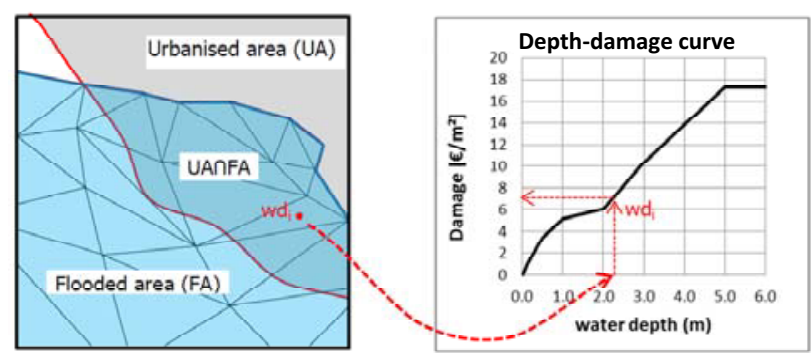

Figure 6. Calculation of damages for a residential area

Each flood risk indicator was "annualised"e by using flood events with different return periods to estimate the long term annual average impacts. For example, the annual average number of people affected is an estimate of the number of people that may be flooded in an average year for each of indicators HU1, HU2 and HU3.

This has been done by producing damageprobability curves. The total area under this curve represents the annualised value of the flood risk indicator, or to put it another way, the long-term average annual value of the flood risk indicator (Figure 7).

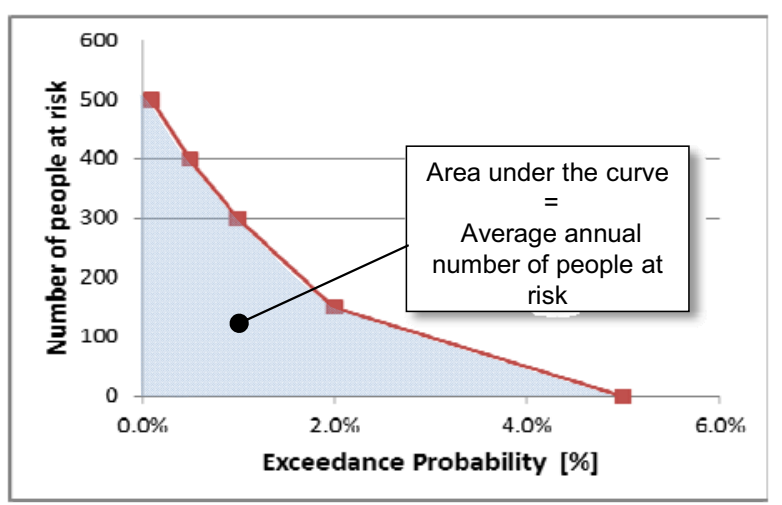

Figure 7. Calculation of annual average values

\subsection{Flood risk results}

The flood risk indicators were combined by weighting each indicator. Whilst the flood risk was calculated as relative numbers, the economic indicators provide a direct economic cost and therefore the combined risk could be converted to economic damages.

The total annual flood risk for the $3,400 \mathrm{~km}$ of high risk rivers in Moldova was estimated to be $€ 56$ million. Almost half is due to direct economic damages and the remainder is due to indirect damages including human and environmental impacts. The 
average annual number of people affected by flooding was estimated to be 5,200 , of which $44 \%$ would be severely affected and $15 \%$ very severely affected.

The risk was categorised as very high, high, medium and low. The risk was plotted for $200 \mathrm{~m} \mathrm{x}$ $200 \mathrm{~m}$ squares for all $3,400 \mathrm{~km}$ of river covered by the assessment. An example is shown on Figure 8. It would be possible to calculate the flood risk on a smaller and more refined grid, but this would have required greater computing effort. In addition, the $200 \mathrm{~m}$ grid was considered suitable for prioritising areas for flood reduction measures.

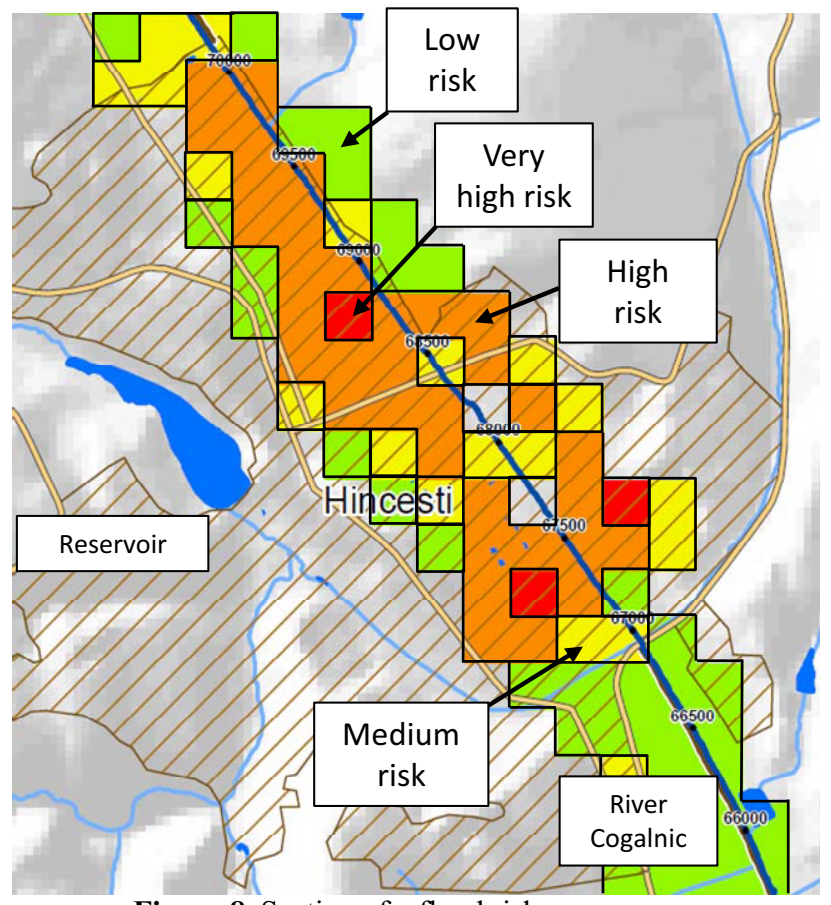

Figure 8. Section of a flood risk map

\section{Objectives and strategies}

\subsection{Objectives for flood risk management}

Objectives for flood risk management were developed and agreed with stakeholders. These are the purposes of flood risk management, and the main objective identified by the stakeholders was to reduce flood risk to people and settlements. Protection of agriculture was also an important objective, but considered to be of less importance than people and settlements.

\subsection{Strategies and strategic options}

A range of strategies to achieve the objectives were identified, and preferred strategic options were selected for each part of the river system using a multi-criteria analysis. The strategic options took account of the existing flood protection infrastructure, which represents a major existing investment in flood protection.
Investment in new flood management measures depends to some extent on the condition of the existing measures: where the existing dykes are in good condition, the amount of repair work would be small, whereas where the dykes are in poor condition, the amount of repair work and associated cost would be high. A detailed condition survey was carried out of the flood protection dykes in order to estimate the probability of failure and the rehabilitation work required.

The main strategic options included the following:

- Rehabilitation and improvement of the existing dyke system, where improvement includes raising of crest levels and the construction of new dykes;

- New or rehabilitated flood storage dams at some locations;

- Enlargement of the river channels at some locations (using two-stage channels to minimise the environmental impact);

- New or improved flood forecasting and warning systems;

- Combinations of options.

Avoidance of increases in flood risk elsewhere was an important consideration in the development of the options, and options that could potentially increase downstream flood risk were combined with flood storage to mitigate this risk at some locations.

A strategic option that provides flood storage and environmental enhancement is to breach dykes and reconnect the river with the floodplain. Whilst this provides overall benefits at some locations, it could make downstream flooding worse for large floods. This is because the timing of filling of the floodplain areas during a flood event is changed by breaching of the dykes. The floodplains would fill earlier in the event and not be available when the flood peak occurred.

The river system in Moldova is highly engineered with straightened river channels and parallel dykes. Re-naturalisation of the river channel was included as an option in some locations.

Strategic options were identified for each part of the river system taking account of the location of the flood risk and constraints. A multi-criteria analysis was carried out in order to identify the preferred strategic options. The analysis involves scoring and weighting each option against a number of different criteria.

An example of a multi-criteria analysis result is given in Table 2, which shows the criteria used in the analysis. In order to calculate values for some of the criteria, particularly the effectiveness and benefit cost ratio of each option, it was necessary to prepare outline designs and calculate approximate costs.

In the example shown in Table 2 , the preferred strategic option is a combination of rehabilitation and improving existing dykes (option SO3), increasing channel capacity using 2-stage channels (option SO5), measures that contribute to environmental enhancement (option SO6) and non-structural 
measures (option SO7).

\begin{tabular}{|c|c|c|c|c|c|c|c|}
\hline Option & $\begin{array}{c}\text { River: Raut (lower section) } \\
\text { Measures }\end{array}$ & \begin{tabular}{|c|} 
Effectiveness \\
(reducing \\
risk)
\end{tabular} & Cost & CBA & $\begin{array}{c}\text { Environmental } \\
(-5 \text { to }+5)\end{array}$ & $\begin{array}{l}\text { Social impact } \\
(-5 \text { to }+5)\end{array}$ & Total \\
\hline SO1 & Repair all existing dykes & 2 & 3 & 8 & -1 & 1 & 47 \\
\hline SO3 & $\begin{array}{l}\text { Rehabilitate and improve dykes in high } \\
\text { risk areas }\end{array}$ & 6 & 3 & 8 & 0 & 1 & 67 \\
\hline SO4 & $\begin{array}{l}\text { Provide more flood storage: new } \\
\text { reservoirs }\end{array}$ & 3 & 3 & 6 & -1 & 2 & 46 \\
\hline SO5 & Increase the capacity of river & 3 & 8 & 8 & 1 & 2 & 63 \\
\hline SO6 & Measures that are compatible WFD & 1 & 5 & 0 & 5 & 3 & 29 \\
\hline SO7 & $\begin{array}{l}\text { FFW, emergency planning and } \\
\text { response }\end{array}$ & 2 & 9 & 6 & 1 & 1 & 49 \\
\hline SO8 & Different approach (SO3+SO5) & 7 & 2 & 8 & 1 & 2 & 77 \\
\hline $\mathrm{SO} 8$ & Different approach (SO3+SO5+SO6) & 7 & 1 & 6 & 3 & 2 & 72 \\
\hline SO8 & $\begin{array}{l}\text { Different approach } \\
\text { (SO3+SO5+SO6+SO7) }\end{array}$ & 8 & 1 & 6 & 5 & 3 & 84 \\
\hline
\end{tabular}

Table 2. Multi-criteria analysis result

\section{Flood management measures}

Flood management measures were then identified for the areas with the greatest flood risk including both structural and non-structural measures. Flood risk is widespread on the rivers in Moldova and a total of 84 structural measures were identified to reduce flood risk for over 100 settlements. Many towns and villages are affected by flooding although the greatest risks are in the major cities of Chișinău and Bălți (Figure 1).

In addition, a total of about 30 non-structural measures were identified including capacity building, improving flood management information, improving inspection and maintenance of infrastructure, land use planning, catchment water retention, soil conservation, flood forecasting and warning, emergency planning and public awareness raising.

Costs were estimated for the measures on the assumption that the works would be carried out by local contractors as far as possible, and therefore local prices were used except where materials (such as new flood gates) and expertise were not locally available. The costs included capital costs of structural measures, costs for non-structural measures and maintenance.

The measures were prioritised based on the urgency of the measure, the magnitude of the reduction in flood risk, the benefit-cost ratio of the measure and the need to develop groups of measures that provide an integrated solution for a flood risk area. Constraints to implementation were also identified as this could affect the timing of implementation.

\section{Phased investment programme}

The phased investment programme was developed by dividing the structural measures into 32 groups, where each group contained the same types of measures in the same river basin and with the same priority. The programme for structural measures was developed taking account of the priority of the measures and the constraints.

The programme for non-structural measures was developed taking account of the dependency between different activities, for example the need for capacity building before certain activities can be undertaken and the need to establish databases and programmes of work before inspection and maintenance activities can be carried out.

\subsection{Structural and non-structural measures}

The programme consists of structural and nonstructural measures to reduce flood risk. The structural measures include:

- Rehabilitation and repair of existing flood protection dykes;

- Improvement of the existing system of flood protection dykes including raising of crest levels to improve the standard of protection and the construction of new flood protection dykes and walls;

- Enlargement of existing river channels in flood risk areas, achieved by the construction of 2stage channels in order to minimise disruption to existing river channels;

- The provision of additional flood storage in reservoirs by rehabilitating and improving existing dams or by the construction of new dams;

- Other measures concerning dams include improvements to dam operation for flood control and the removal or rehabilitation of unsafe dams; 
- Measures to re-naturalise sections of river to enhance the ecology and provide some retention of flood water

The non-structural measures include:

- Development and use of flood hazard and flood risk maps for flood management planning, public information and emergency planning;

- Land use planning measures to reduce development in flood risk areas;

- Soil and water conservation;

- Improved management of existing dams and reservoirs;

- Maintenance of flood protection infrastructure;

- Improved flood forecasting and warning;

- Improved emergency planning;

- Raising the awareness and preparedness of the public in relation to flooding;

- Capacity building of relevant institutions;

- Technical Assistance to support the nonstructural measures.

\subsection{Timescale and costs}

It is likely that the phased investment programme will begin in 2017 and continue until 2036. The programme will be carried out in the following three phases:

1. Short-term measures (year 1 to year 7)

2. Medium-term measures (year 8 to year 12)

3. Long-term measures (year 13 to year 20)

The overall programme cost for the phased investment programme is about $€ 295$ million for structural measures and $€ 120$ million for nonstructural measures including maintenance.

\subsection{Short-term investment programme}

The Short-Term Investment Plan includes structural measures for the River Prut, the River Dniester, the River Bîc at Chișinău and the River Răut and tributaries at Bălţi. The cost of the structural measures is about $€ 70$ million together with about $€ 37$ million for non-structural measures including maintenance.

\section{Implementation}

In parallel with the development of the plan, a programme of capacity building was undertaken to facilitate the handover of the Plan to local staff. This included handing over the modelling system and providing training to staff from the organisations responsible for flood management in Moldova. The project team included local staff, which also helped to increase the local flood risk management capacity.

The programme will be implemented by existing national government organisations. The lead organisation will be Apele Moldovei, which is the agency within the Ministry of Environment that is responsible for water management in Moldova.

There will be a need to increase the number of staff employed by these organisations for flood management together with associated training and capacity building so that the organisations have the capabilities to undertake the required tasks.

The Master Plan also includes recommendations for changes to the existing flood risk management responsibilities in order to optimise the use of resources and avoid overlaps between different government departments and organisations.

\section{Conclusions}

A Master Plan has been developed for flood risk management in Moldova that includes a range of structural and non-structural measures. The technical achievements of the project include the following:

1. National flood hazard and flood risk modelling and mapping has been undertaken for the Preliminary Flood Risk Assessment.

2. Fully 2-dimensional (2D) river and floodplain models of major rivers (up to $500 \mathrm{~km}$ in length) including protected floodplains have been created from a range of data including $1 \mathrm{D}$ river cross-sections and $2 \mathrm{D}$ floodplain topography.

3. The use of GPU technology has improved the speed of computer simulations. It is recognised that this is evolving technology but it provides the opportunity to construct larger and more complex models that can be run in a reasonable time.

4. A flood risk analysis has been carried out that evaluates and combines risk from a range of social, economic and environmental flood impacts.

5. Preferred strategic options for flood risk management have been identified for each part of the river system using multi-criteria analysis.

6. The measures required to implement the strategic options have been identified and prioritised in order to provide a programme of measures to be implemented over a 20 -year period.

\section{References}

1. EIB (2007). Guide for preparation of flood risk management schemes. Report MCR4100, funded by the European Investment Bank, December 2007. 
2. ENVSEC (2012). Reducing vulnerability to extreme floods and climate change in the Dniester river basin (Dniester III floods \& climate), project under the Environment and Security Initiative in Eastern Europe (ENVSEC) initiative by UNEP, UNECE and OSCE.

3. Nikolayeva, L. (2012), Reducing vulnerability to extreme floods and climate change in the Dniester river basin (Dniester III floods \& climate): Summary, paper available at: http://www.zoinet.org/web/sites/default/files/pu blications/Summary Baseline studies Dniester floods climate project 0.pdf

4. EAST AVERT (2013 and ongoing), Prevention and flood protection in Siret and Prut river basins, collaborative project between Romania and Moldova, http://east-avert.org/

5. Alcrudo, F. and Mulet-Marti, J. (2005). Urban inundation models based upon the Shallow Water equations. Numerical and practical issues. In F. Benkhaldoun, D. Ouazar \& S. Raghay (eds), Proceedings of Finite Volumes for Complex Applications IV. Problems and Perspectives. Hermes Science. pp 1-12.

6. Weisgerber, A., Gutierrez Andres, J., Wilson, G., Marias, F., Karanxha, A., Clarke, R.T. and Millington, R. (2010). Physical-computational modelling comparison in Ireland. Proceedings of the International Symposium on Hydraulic Physical Modelling and Field Investigation.

7. Lhomme, J., Gutierrez-Andres, J., Weisgerber, A., Davison, M., Mulet-Marti, J., Cooper, A. and Gouldby, B. (2010). Testing a new twodimensional flood modelling system: analytical tests and application to a flood event. Journal of Flood Risk Management, 3: pp 33-51.

8. Defra/Environment Agency (2005). $R \& D$ outputs: Flood risks to people, Phase 2, Guidance Document. Report FD2321/TR2, HR Wallingford on behalf of Defra and the Environment Agency, April 2005, pp 15-16. 